\title{
SPONTANEOUS REGRESSION OF A DESMOID TUMOUR
}

\author{
N. H. JENKINS, L. S. FREEDMAN, B. MCKIBBIN
}

From the University of Wales College of Medicine, Cardiff

\begin{abstract}
A 15-year-old girl presented with a very large desmoid tumour in her buttock; it extended into the pelvis and thigh and would have required hindquarter amputation for its removal. This was not performed and the tumour underwent spontaneous regression. Fourteen years later the patient is alive and well. The suggestion is made that in some of these cases a more expectant approach to treatment might be justified for what is essentially a non-malignant condition.
\end{abstract}

Musculo-aponeurotic fibromatosis (desmoid tumour) is an uncommon condition and may occur in abdominal or extra-abdominal sites. It may also occasionally occur as part of Gardner's syndrome in association with colonic polyps, sebaceous cysts and exostoses (Goligher 1980).

The tumours are of fibroblastic origin and develop within skeletal muscle or surrounding aponeuroses. Although benign, they are locally aggressive especially around the pelvis (Carnesale and Pitcock 1980); they are also prone to local recurrence after excision and a wide local clearance is therefore usually recommended, preferably including the whole of the affected muscle (Cole and Guiss 1969). In spite of this, the natural history of this unusual condition does not appear to be well documented, although its behaviour has been noted to vary with the anatomical location (Enzinger and Shiraki 1967).

We report a case of a large pelvic tumour arising in a patient who was then offered only symptomatic treatment.

\section{CASE REPORT}

A 15-year-old girl presented with a history of several months' left-sided sciatica; her pain was constant but unrelated to movement or activity. Examination revealed a large mass filling the left buttock, arising from within the musculature and extending anteriorly to the adductor compartment of the thigh and inferiorly to the mid-thigh level. There was also a mass $6 \mathrm{~cm} \times 8 \mathrm{~cm}$ in the left iliac fossa which on rectal examination seemed to

N. H. Jenkins BSc, FRCS, Orthopaedic Registrar

L. S. Freedman, FRCS, Orthopaedic Senior Registrar

Prince of Wales Orthopaedic Hospital, Rhydlafar, Cardiff CF5 6XG, Wales.

B. McKibbin, MD, MS, FRCS, Professor of Traumatic and Orthopaedic Surgery

University of Wales College of Medicine, Cardiff Royal Infirmary, Cardiff CF2 ISZ, Wales.

Requests for reprints should be sent to Mr N.H. Jenkins.

(C) 1986 British Editorial Society of Bone and Joint Surgery $0301-620 \mathrm{X} / 86 / 5145 \$ 2.00$ be continuous with the mass in the buttock through the greater sciatic notch. This was subsequently confirmed by retroperitoneal air insufflation. Movements of the hip joint were extremely limited. There were no lesions elsewhere in the body and a chest radiograph was clear. A barium enema, intravenous pyelography and sigmoidoscopy were also normal.

A biopsy was performed from the most distal part of the tumour at the back of the thigh. It was there found to be arising from the musculature, principally from the gluteus maximus and the hamstrings; the sciatic nerve was totally surrounded by tumour. Subsequent histological examination of the material removed revealed an infiltrating mass of fibrous tissue with degeneration of the adjacent muscle. There was no evidence of malignant change and the tumour was considered to be a benign musculo-aponeurotic fibroma (desmoid tumour).

The patient was seen by a number of surgeons whose unanimous decision was that adequate local excision was impossible without irretrievable damage to the limb, and that a hindquarter amputation would therefore be necessary. This was considered but, in view of the patient's age and the fact that the condition was nonmalignant, it was decided to continue observation and to treat her symptoms.

However, the main mass continued to grow, reaching its maximum size two years after her initial presentation. At this stage there was a huge swelling of the buttock which was clearly visible through the patient's clothing and the hip had become fixed in a position of flexion and medial rotation. Satellite lesions had developed behind the left knee and severe flexion contracture of this joint developed. By then, however, the patient's sciatica had largely subsided. At this stage elongation of the hamstring tendons was performed to provide a satisfactory correction of the knee-flexion deformity. Despite these events, the patient remained active and uncomplaining and successfully took her matriculation examinations.

About five years after the initial presentation the 
tumour began to regress spontaneously, initially from the adductor group. The communication between the pelvic and buttock masses resolved and the hip became mobile. By 10 years after its appearance the tumour was no longer palpable in the lower limb; the pelvic mass also diminished considerably in size, although it was still just palpable.

Seven years after the initial presentation a painful lump had developed in the left calf. Clinically this appeared to be a lesion similar to that in the buttock and no biopsy was undertaken. It expanded over the following year and gave rise to an equinus deformity of the ankle which was treated by elongation of the tendo calcaneus. Soon afterwards this mass also underwent spontaneous regression and disappeared completely six years after it was first noticed.

At review 14 years after the development of the initial tumour the patient remains in good health with no palpable mass in the thigh and only a small mass in the pelvis as previously described. There are no residual contractures in the hip which has a full range of movement, the knee is fully mobile and there is no residual equinus deformity. Despite the residual pelvic mass, the patient has recently had a vaginal delivery of her first child.

\section{DISCUSSION}

The treatment of large desmoid tumours, particularly in the region of the pelvis, poses a rather unusual surgical problem for while the lesion shows the tendency to local invasion characteristic of malignant tumours, there is no risk of distant metastasis. Because of this local behaviour, wide excision is usually recommended even though this means that in some anatomical locations this can only be achieved by major amputation; one such patient was reported by Barber, Galasko and Woods (1973), for whom a hindquarter amputation was required for a buttock lesion similar to the one reported here. There is inevitably something repugnant about having to perform a mutilating operation for a condition which is essentially benign and, indeed, one which many pathologists would not accept as being a true tumour at all.

It was for these reasons that operation was withheld in the present case where the prospect of a hindquarter amputation in an attractive young girl of 15 was particularly unappealing. In the event, the outcome was a happy one. The tumour, after a period of continuing growth, subsequently underwent significant involution so that major surgery was not required. As a result she is now married with a family and enjoys a normal range of activities. However, because of the small pelvic mass which remains, continuing supervision will be required.

It is important not to deduce too much from a single case but it would appear that this dramatic regression of a desmoid tumour is not unique. Strode (1954) and Dahn, Jonsson and Lundh (1963) have reported spontaneous regression in females at the onset of either the menarche or the menopause, suggesting that hormonal change might be involved. In a recent paper Cady (1985) also commented that spontaneous regression has been previously recognised but he gave no details. Enzinger and Shiraki (1967) reported a single case of desmoid tumour in the shoulder region in which the tumour recurred after local excision; the patient refused further operation and the recurrent mass regressed spontaneously over a number of years.

When the histories from these admittedly few cases are considered - together with the knowledge that the condition is not truly neoplastic - one is inevitably led to speculate that if a more expectant course were adopted in such cases, the need for operation might be avoided since distant metastases may be discounted. Desmoid tumours are extremely slow-growing, and the decision not to operate can always be reversed if increasing size appears likely to compromise important anatomical structures. It also seems that any local deformity can be satisfactorily treated by lengthening contracted tendons directly and by leaving the abnormal tissue undisturbed.

It is impossible to say whether this tendency to spontaneous regression is present in a significant number of cases, but further investigation seems justified, especially in those cases where mutilation would otherwise result. However, if the decision to treat a cases expectantly is made, it should also be remembered that, in the patient described in this report, the lesion enlarged significantly after initial presentation before any regression began. In such circumstances pressures to operate are inevitable and the observer must keep the essential non-malignancy of the lesion constantly in mind.

\section{REFERENCES}

Barber HM, Galasko CSB, Woods CG. Multicentric extra-abdominal desmoid tumours: report of two cases. J Bone Joint Surg [Br] 1973;55-B:858-63.

Cady B. Management of desmoid tumours. Am J Surg 1985;149:312.

Carnesale PG, Pitcock JA. Tumors. In: Edmonson AS, Crenshaw AH, eds. Campbell's operative orthopaedics 6th ed. St Louis etc: CV Mosby, 1980; 2:1277-1378.

Cole NM, Guiss LW. Extra-abdominal desmoid tumors. Arch Surg 1969;98:530-3.

Dahn I, Jonsson N, Lundh G. Desmoid tumours: a series of 33 cases. Acta Chir Scand 1963;126:305-14.

Enzinger FM, Shiraki M. Musculo-aponeurotic fibromatosis of the shoulder girdle (extra-abdominal desmoid): analysis of 30 cases followed up for ten or more years. Cancer 1967;20:1131-40.

Goligher JC. Surgery of the anus, rectum and colon. 4th ed. London: Baillière Tindall, 1980.

Strode JE. Desmoid tumors particularly as related to their surgical removal. Ann Surg 1954;139:335-40. 